\title{
Piñeiro e os albores da «nova narrativa» galega
}

\author{
M. Teresa Bermúdez Montes \\ Universidade de Vigo
}

Resumo: Ramón Piñeiro foi a figura clave do galeguismo de posguerra e desempeñou, incuestionablemente, un papel central no movemento de recuperación cultural galega que liderou a editorial Galaxia. Desde esa posición, mantivo estreitos contactos cos novos autores que pretenderon renovar a narrativa galega, aqueles englobados tradicionalmente na nova narrativa. Neste traballo pretendemos poñer de manifesto o carácter de eixo de Piñeiro, tanto para aqueles que se opoñían ás súas ideas estéticas, como para aqueles que as asumiron ouaqueles que non chegaron a manifestarse.

Palabras clave: Literatura galega século XX, Ramón Piñeiro, nova narrativa.

\begin{abstract}
Ramón Piñeiro was the key figure in the postwar galeguismo (Galician nationalism). He played unquestionably a central role in the Galician cultural recovery movement led by the publishing house Galaxia. From that position, he maintained close contacts with the young authors who tried to renew Galician narrative, those traditionally encompassed in the nova narrati$v a$. In this article we try to show how Piñeiro was the axis of this process, both for those who opposed his aesthetic ideas and those who took them and even those who failed to manifest themselves.
\end{abstract}

Keywords: Galician Literature 20th century, Ramón Piñeiro, Galician's nova narrativa.

\section{INTRODUCIÓN}

As Letras Galegas honraron en 2009 a Ramón Piñeiro (1907-1991), filósofo, intelectual e verdadeiro eixo vertebrador do galeguismo de posguerra. Piñeiro foi o núcleo a partir do cal se artellou a vida intelectual e cultural da segunda metade do século XX, como líder do grupo galeguista que materializou a súa actividade no proxecto Galaxia. 
Supervivente do galeguismo de preguerra, foi un dos nexos de unión coas novas xeracións de escritores galeguistas que agroman a partir dos 50, a chamada «xeración da Noite». Membro dunha xeración de transición á que lle correspondeu servir de ponte co labor da xeración Nós, estableceu unha particular relación con eses mozos que non viviran a guerra civil, nin coñecían por vivencia propia o período da República.

Por isto, imos ocuparnos da relación entre Piñeiro (representante do pensamento da xeración Galaxia) e algúns membros destacados da denominada «xeración da Noite» (Franco Grande 1985) e, fundamentalmente, cos primeiros «novos narradores». A vontade de renovación foi o punto de encontro de posicionamentos estéticos (Rodríguez Mourullo, Casal ou Méndez Ferrín) que se materializaron ao longo dos anos nunha pluralidade de traxectorias literarias e intelectuais.

\section{O PENSAMENTO DE PIÑEIRO. UNHA CONCEPCIÓN DA CULTURA GALEGA. A PROPOSTA DUNHA ESTÉTICA NACIONAL}

A exposición do pensamento de Piñeiro ten como obxectivo a plasmación da «personalidade espiritual» de Galicia. A posición intelectual do galeguismo de Piñeiro proxéctase na súa posición cultural (e, polo tanto, no plano literario). A súa ética dá lugar a unha estética, coherente coa súa análise da mundo e do ser humano. Esta orientación político-estética condúcenos ao que se deu en chamar culturalismo promovido na Galicia da «longa noite de pedra» a través de Galaxia, isto é, por Piñeiro (Forcadela 2005).

Ramón Piñeiro formulou en diferentes textos a súa estética, derivada do reflexo de Galicia, no marco da etapa de nacionalismo literario que estaba a vivir a literatura galega (González Millán 1995: 67-81). Cómpre sinalar que a exposición do pensamento de Piñeiro levouse a cabo adoito de maneira dialóxica. En efecto, como veremos, é moi frecuente que se sirva do xénero epistolar para desenvolver as súas ideas e defender os seus argumentos, sexan en forma de cartas abertas (públicas) ou na correspondencia privada. Algúns destes textos foron reunidos en volumes como Paisaxe e cultura (Piñeiro 1965) ou Olladas no futuro (Piñeiro 1974), mais viran a luz inicialmente en forma de prólogos («Carta a Daniel Cortezón Álvarez», n'As covas do Rei Cintolo), artigos ou cartas abertas.

Piñeiro comezou a tratar o seu proxecto literario-identitario galego nos inicios da década dos cincuenta, aínda que xa en 1949 apuntara as súas liñas básicas no texto titulado «O libro que nos debe Ánxel Fole» (La Noche, 1949). A potenciación da paisaxe enlaza indirectamente co tratamento literario de motivos folclóricos e populares, elaborados desde unha perspectiva culta. Así, a estética baseada no elemento popular de Ánxel Fole foi louvada ata o final da súa vida por Piñeiro, quen nun artigo dedicado á colección Terra brava destaca a «absoluta simultaneidade no campo cercado da minoría culta e no campo aberto e cálido do mundo popular» (Piñeiro 1987: 113-114). Nun texto revelador dos anos cincuenta, a «Carta a Novoneyra», salienta a «identificación sentimental coa Te- 
rra» do poeta e o reflexo da «verdade esencial da realidade galega» e do «esprito galego en canto realidade coleitiva». Así, afirma:

Na vida da cultura galega, a Terra é un elemento aitivo i esencial. A nosa realidade cultural ven a ser a integración do humán e mailo telúrico, cualidade peculiarísima da nosa cultura, quizáis a máis difícil de comprender pra os alleos. Sin a base telúrica, a nosa espresión puramente humán é parcial, incompleta, sometida a perene vaguedade... (...) Porque a cultura galega nace da peculiar situación espritoal do home galego, que non é, como na maoría dos casos, o froito, o refrexo da intensa e integral relación do home cos outros homes. Eiquí a situación radical do home non consiste fundamentalmente na relación cos outros homes, senón na relación coa Terra; consiste na súa relación coa «vida cósmica» máis que na súa relación coa «vida social» (Piñeiro 1956b: 16-17).

Xa desde os inicios da década dos cincuenta expuxera os alicerces da súa «filosofía da saudade», nun texto fundamentado no pensamento heideggeriano no que xa fala de «personalidade espiritual», e afirmaba: «Ninguén nega que cada pobo vai refrexando a súa persoalidade espritoal na creación d-unha literatura, d-un arte ou d-unhas istitucións sociás peculiares» (VV.AA. 1951: 7).

Estes eran os valores estéticos que se pretendía transmitir ás novas xeracións, coa mirada posta no enlace coa tradicón de preguerra, isto é, coa ideoloxía de Nós. Así, sempre coa «realidade espiritual» de Galicia como centro de toda reflexión e produción artística, na súa correspondencia con Allué Andrade Piñeiro adoutrina neste sentido:

Tendo en conta que as formas fundamentás son constantes, i o contido sempre novo, en cada tempo i en cada individuo, o que nós debemos de percurar é que as nosas aportacións á cultura galega acaden a fondura esencial das «formas fundamentás» e acaden a plenitude orixinal do «contido» do noso tempo e da nosa persoalidade individual. Somentes así poderemos facer algo con valor trascendente, con categoría de permanencia. Non é empresa doada, mais os que nos entreguemos a ela co sentimento de cumprir un deber histórico, temos que nos someter a tan cobizoso risco.

(...) Igoal debería ocurrir coas demais creacións da cultura. Por ista vía é por onde se chega á identificación plena e total co verdadeiro ser de Galicia. De acordo contigo en que polo camiño da «imitación» do pasado ou do puramente típico non se chega moi lonxe (Piñeiro 2005: 40-41). [Cursiva nosa]

Máis adiante, expuxo detalladamente a súa posición no artigo «Carta a Álvaro Cunqueiro, trovador galego, falándolle dos males presentes de Europa e do seu remedio, dende a ladeira dun castro lugués» (Piñeiro 1951: 103-107, Piñeiro 1974: 19-26). Cunha actitude europeísta, pretende definir cal é a situación de Galicia en relación co continente europeo e establecer, en función do seu diagnóstico, cal é o papel de Galicia no ámbito da cultura europea. E Piñeiro chega á conclusión de que a achega dos galegos —en canto europeos máis libres e aínda vinculados coa natureza e coa forza creativa da imaxinación- 
debe ser mostrar aos demais que a reconciliación coa liberdade perdida é posible, que a recuperación da imaxición é posible e que a plasmación dunha vivencia íntima da paisaxe e do contorno natural é tamén posible. En realidade, a teoría presente na «Carta a Álvaro Cunqueiro» representa a continuidade coas formulacións de Vicente Risco na preguerra, isto é, coas concepcións herdadas da Xeración Nós por Piñeiro (Forcadela 2005: 15). Así, téñense detectado no texto

algúns dos motivos expostos por Otero Pedrayo no seu Ensaio histórico sobre a cultura galega (1982: 23) cando afirmaba a súa convicción de teren os galegos unhas características espirituais determinadas, entre as que salientaba a ausencia dunha dogmática ríxida, a tendencia ao soño, a ironía, a sucesión arbitraria dun tonus exaltado e deprimido baixo a aparente solidez dunha vida disciplinada e o desexo vago dunha cousa (Forcadela 2005: 21).

En definitiva, para Piñeiro, a personalidade espiritual galega, ao proxectarse na cultura, materializaríase no cultivo da imaxinación, co sentimento da paisaxe, o lirismo e do humorismo como pilares da galeguidade nas producións culturais. Esta liña de pensamento, tal como ten sinalado moi acertadamente Forcadela (2005), baséase no establecemento dunha oposición clara entre uns valores «estranxeiros» (racionalismo, desnaturalización) — presentados como negativos ou en todo caso insuficientes- e uns valores «propios» (imaxinación, arte, liberdade, individuo), presentados de xeito positivo:

Da reflexión anterior xurdirá a contraposición entre Europa e Galicia. Mentres Europa se sitúa claramente no ámbito da racionalización e da Historia, a Galicia cumpriríalle o papel de ser espazo da liberdade, da arte, da natureza e do individualismo. (...) [A] Galicia correspóndelle a responsabilidade de facer regresar a Europa a presenza do natural, na medida en que o europeo perdeu o contacto co mundo natural, coa liberdade imaxinativa, coa arte como idea cultural (Forcadela 2005: 13).

Por tanto, existe un programa para situar dun determinado xeito, e non doutro, a cultura galega no ámbito das literaturas europeas, isto é, unha proposta de intervención na arte «europea, á que se pretende chegar desde Galicia» (Forcadela 2005: 14). A partir de mediados dos cincuenta chegarían a materializarse as dúas tendencias estéticas que opón Piñeiro: a autenticamente galega e esencialmente vinculada á Terra, como encarnación da «personalidade espiritual» que recollería o espírito do país, fronte á aquela vinculada co tempo presente, comprometida coa Historia.

As oposicións mencionadas (liberdade-lei, imaxinación-razón, arte-ciencia, individualismo-socialismo) vertebraranse, pouco tempo despois, en dous movementos literarios totalmente característicos da época: o Realismo máxico e a Nova Narrativa Galega (Forcadela 2005: 112).

Posteriormente, Piñeiro escribe o prólogo para As covas do rei Cintolo (1956), obra marcada por un claro carácter fantástico, na liña de reelaboración 
dos mitos medievais na que destacara Cunqueiro. Nese texto ( Carta a Daniel Cortezón Álvarez»), defende unha estética na que a imaxinación ocupa un lugar central, como ferramenta de expresión da «realidade espiritual» e do «ser esencial», sempre con Cunqueiro como cumio e referente da súa estética literaria. Continúa neste o desenvolvemento da idea da que a conservación da auténtica liberdade sería un trazo que distinguiría e identificaría a Galicia fronte ao outros pobos do mundo. Piñeiro diserta sobre o mundo contemporáneo, dentro do cal destaca unha illa excepcional: a «gran zona da poboación galega que aínda non perdeu a vivencia da libertade» (Piñeiro 1956: 19). Establece o autor unha relación entre literatura fantástica, galeguidade e liberdade, fronte á presenza do absurdo, da angustia, da violencia, a problemática existencial e a deshumanización. Así, asegura:

O home que a literatura dos nosos días refrexa é «o home sin libertade». Non refrexa ó home inteiro e verdadeiro, dono de sí, ou seña, o home cuia eisistencia está dotada de sentido e que asume a suprema responsabilidade de realizalo; pola contra, eiquí trátase dun home cuia eisistencia carece de sentido propio e da correspondente independencia pra o desenrolar. (...) Si a tendencia imaxinativa de «As Covas do Rei Cintolo» contrasta coa orientación literaria predominante na época non é por capricho singular do autor senón pola súa identificación coa tendencia fundamental do mundo galego no que nós vivimos (Piñeiro 1956a: 14-20).

En todo caso, o obxectivo de Piñeiro nos seus textos era deseñar unha estética nacional, mais tamén atraer a Cunqueiro cara á literatura galega, para contribuír a que se cumprise este proxecto estético, por ser o mindoniense un escritor de calidade, galeguista e sen problemas co franquismo. Desde Galaxia considerábase a Cunqueiro capaz de levar a termo unha modernización da literatura galega desde dentro, loitando contra o folclorismo pero sen abandonar o endocentrismo:

Cunqueiro i la seva obra es convertirien així en el rostre i el cos d'una Galícia emergent i resistent, d'una Galícia gens acomplexada que feia servir la cultura - support per a un discurs polític galleguista - com a fonament de la seva diferència ${ }^{1}$ (González Fernández 2001).

Por outra banda, o propio Piñeiro confirmaba o papel que se lle pretendía adxudicar a Cunqueiro no precario sistema galego, ao afirmar: «Fole e máis Cunqueiro son espoñentes representativos, cada ún á súa maneira, da pervivencia aitual desa libertade [do ser humano] no ámbito galego» (Piñeiro 1956: 19).

Pódese considerar que Piñeiro expón así a que sería a ideoloxía común do conxunto dos homes de Galaxia, pois aínda que nalgún caso non existise acordo

\footnotetext{
${ }^{1}$ «Cunqueiro e a súa obra converteríanse así no rostro e no corpo dunha Galicia emerxente e resistente, dunha Galicia nada acomplexada que utilizaba a cultura — soporte dun discurso político galeguista - como fundamento da súa diferenza» (Tradución nosa).
} 
total, as discrepancias ficaron no ámbito da correspondencia privada ${ }^{2}$. Pola contra, as ideas vertidas nesta carta terán resposta tanto pública como privada por parte da nova xeración. A contestación pública chegaría pouco despois en forma de carta aberta («Carta a Manuel Antonio», 1957), nunha polémica que fará agromar o enfrontamento estético e, con algúns dos novos autores, político, como veremos. No ámbito da correspondencia privada, a cuestión foi obxecto de debate epistolar entre Piñeiro e Xosé Luís Allué Andrade, quen non coincide con esa valoración de Piñeiro de que a ficción teña que ser central na literatura galega.

O debate continúa arredor dunha controvertida afirmación de Piñeiro sobre a ausencia de sintonía perfecta entre «entre a realidade espritoal de Galicia i a realidade espritoal da época», que foi entendida como un reproche cara ás innovacións dunha narrativa como a de Mourullo, por exemplo. Afirma Piñeiro así que «a crisis espritoal creada pola socialización do home contemporáneo é en Galicia menos profunda e aguda que noutras partes» (Piñeiro 2005: 88). E insiste na defensa do mesmo posicionamento na correspondencia con Allué Andrade:

Precisamente nos nosos días trátase de saír desa crisis polo camiño de unha revalorización da libertade, dándose o caso de que nesa direición Galicia está bastante mellor situada que outras comunidás. (...) E, craro está, quenes queiran enriquecer o diálogo cultural do Mundo aportando o punto de vista que o Mundo ofrece visto dende a realidade que se chama Galicia, teñen que descobrir e crear esa perspeitiva peculiar, única, que solo dende Galicia se ofrece. Porque a perspeitiva que o Mundo ofrece dende París, dende Montevideo ou dende Nueva Delhi serán os franceses, os urugayos ou os indios quenes a descubran, definan e creen. Cando se fala da universalidade da cultura caise frecuentemente na confusión da natureza da cultura — que é sempre unha realidade singular, concreta - co valor da cultura —que é trascendente, universal-. Falando con rigor non hai Cultura senón culturas (en plural). O que se chama Cultura non pasa de ser unha abstracción fundada nos valores trascendentes das culturas concretas e reales (Piñeiro 2005: 88-91).

Con todo, unha vez expostas as súas ideas ${ }^{3}$, Piñeiro móstrase tolerante coa diferenza de gustos e mesmo semella valorala positivamente (carta a Allué, 24-3-1957):

${ }^{2}$ A posición defendida por Piñeiro, con ser predominante, non era hexemónica no seo do grupo Galaxia, como testemuña Celestino Fernández de la Vega, outro representante da vella xeración, nunha carta dirixida a un representante da nova xeración, Allué Andrade (16-3-1957): «Tú sabes muy bien — lo sabemos todos_ que la cultura gallega es algo muy frágil y delicado. (...) Libros como los de Cortezón o el Macías desde el punto de vista de la salud de una cultura son, a mi juicio, infecto-contagiosos y contra ellos hay que defender a nuestra naciente cultura gallega. Defensa que, para ser eficaz, ha de hacerse sin escándalo, en privado» (Piñeiro 2005: 142-143).

3 Nalgunha ocasión Piñeiro chega a relativizar o alcance do seu maxisterio e matiza (11-61957): «Tampouco creo que a libertade única, ou fundamental, seña a da vía imaxinativa. Tan importante coma esta é a da vía humorística. E moito máis importante aínda, a alternancia das dúas. De tódolos xeitos, o meu prólogo a As covas do rei Cintolo non é unha teoría xeral da cultura galega» (Piñeiro 2005: 95). 
Por eso é posíbel que, dentro do mundo do arte, poida haber diverxencia e hastra antagonismo de gustos persoais, cousa da que, ó cabo, témonos que alegrar fondamente, pois é o millor espoñente da ilimitada riqueza do esprito (Piñeiro 2005: 87-92).

Por outra banda, o discurso de Piñeiro tamén contaba con defensores entre os representantes das novas xeracións, como Franco Grande - estudante galeguista en Compostela e escritor-, quen destacou a relación entre a fantasía e o humor na obra do mindoniense e recolle a idea da oposición entre literatura da época e literatura galega, en artigos dedicados a Fole e a Cunqueiro:

E así como unha boa parte da literatura do noso tempo nos dá a visión literaria dun dos dramas máis arrepiantes da aventura do home no seu paso por este mundo, a literatura de Cunqueiro - chea de frescura imaxinativa, de graza e de humor, dános tamén a visión dunha das moitas dimensións do home: o mundo máxico, o mundo da imaxinación, o mundo do humor, ao cabo, o mundo da libertade individual (Franco Grande 1968: 416).

Franco Grande viviu desde a perspectiva do escritor mozo as diferentes respostas que suscitou a estética propugnada nos textos de Piñeiro e valorou os acontecementos da época, décadas máis tarde, deste xeito:

Na miña opinión, cando Piñeiro escribía eses prólogos está defendendo unha determinada estética, sen dúbida. E no fondo está negando outras cousas, como no prólogo de Cortezón, por exemplo. Aí vese que lle ten certa inquina á novela americana tal como el a interpreta, pois el consideraba que a de Faulkner era unha novela violenta (...). Sen dúbida ningunha, Piñeiro quería ser, nese momento, unha especie de orientador dos camiños que debía seguir a literatura galega. Ao mellor tampouco era só iso, senón que consideraba que había unha veta (Cunqueiro, Cortezón) que se debía apoiar e cultivar. (...) De todos modos, podo asegurar que isto facíao coa mellor intención do mundo. El non tiña outro norte que a continuidade do galeguismo, e potenciar as posibilidades de Galicia. El quixo asumir a través de Grial o papel que Ortega y Gasset tivera a través da Revista de Occidente, e ser un pouco orientador, o papel que lle gustaba (Bermúdez 2002: LXXIX-LXXX).

En definitiva, a fidelidade «ás esencias da caste» (Lorenzana 1965) e o enraizamento na Terra e na tradición galega eran condicións esixibles, ao entender do grupo galaxiano, aos escritores que quixesen crear literatura verdadeiramente galega.

\section{INNOVACIÓN E EVOLUCIÓN}

Son fundamentais as relacións dos escritores da época cos integrantes da Xeración Galaxia, que eran os verdadeiros «axentes da institución literaria» (Noia 2002) no ámbito galego. Iso é especialmente relevante no caso dos pertencentes á nova xeración, aqueles que trataban de introducirse na tradición galega e de enlazar, vencendo as dificultades da época, cos superviventes do galeguismo de 
preguerra. Piñeiro refírese á importancia do relevo xeracional en carta a Allué (23-10-1958):

Ó irense os petrucios, a responsabilidade do noso destino cultural vai recaendo plenamente nas novas xeneracións. Non tedes máis remedio que asumir esa responsabilidade os que estades en condicións de a afrontar con plena conciencia (Piñeiro 2005: 113).

Como líder galeguista que procuraba a continuidade do proxecto, a actitude de Piñeiro era claramente positiva cara ao labor que só podían levar a cabo as novas xeracións, isto é, a continuidade da cultura galega. Así llo comunica a Allué (26-10-1953):

A túa obra non será soio túa: será «nosa», será de Galicia. A cultura galega acaba de incorporar unha nova espranza. Os que sabemos que a persoalidade espritoal de Galicia descansa unicamente na felicidade da súa cultura, temos que nos folgar de que ista se afiance e se renove (Piñeiro 2005: 35-36).

Con todo, a desconfianza de Piñeiro respecto dos criterios dalgúns mozos fíxose patente en diferentes ocasións, nos intercambios epistolares cos seus compañeiros de xeración. Así, a propósito do pintor e poeta Tomás Barros e da posibilidade de que colabore con Grial desde o estranxeiro, escribe a Ricardo Carballo Calero (31-5-1951):

[A Barros] cando leve ahí algún tempo e se teña orientado por aló pódeselle pedir algunha nota sobre o movimento pictórico en París ou sobre algunha cousa de por alí que resulte interesante para a seición europea de Grial. Máis ben notas que traballos longos, pois co-ista xente nova compre ter algo de precaución porque adoitan a ter uns criterios que non sempre coinciden co que nós nos propoñemos facer. Por exemplo, as opinións poéticas do mesmo Barros, tendo en conta os xuicios que che manifestan en col dos libros de «Benito Soto», non deixan de ser un pouco raras (pol-o menos na parte que eu conozo) (Alonso Girgado 2004: 29). [Cursiva nosa]

Percíbese na correspondencia con Carballo Calero un ton diferente daquel empregado con Allué Andrade. Neste caso, prodúcese unha complicidade propiciada polas referencias, opinións e criterios estéticos compartidos, desde a madurez. Abrolla así nalgunhas cartas a prevención cara aos puntos de vista dos máis novos.

En todo caso, a órbita cultural de Galaxia non permanecía en absoluto allea ás novidades e ás tendencias internacionais. Na revista Grial viron a luz, ao longo deste período, diversos artigos en que se daba conta dos movementos culturais, facéndose eco ou analizando as súas características ${ }^{4}$. Por outra banda, o ves-

4 V. M., «Os persoaxes da nova novela», Grial 8, 253-254; Anónimo, «Robbe-Grillet e a novela», Grial 9, 377-378; Lorenzana, S., «Narradores e teóricos do "nouveau roman”», Grial 19, 5162; Lorenzana, S., «O mundo de Michel Butor», Grial 31, 111-112; Lorenzana, S., «Leendo a Kaf- 
pertino La Noche acollía adoito nas súas páxinas artigos nos que Miguel González Garcés e o profesor Varela Jácome poñían ao alcance do público as novidades da narrativa contemporánea ${ }^{5}$.

O feito foi que se deu —-mercé ás innovacións e á rebeldía dalgúns dos novos escritores que se incorporan á narrativa en galego - unha oposición entre dous modelos estéticos, entre dous xeitos de concebir a literatura galega: por un lado, o centrado nunha hipotética «personalidade espiritual» e, por outro, o enfrontado a ese dirixismo estético e conectado coa problemática da época:

Resulta igualmente moi significativo que a polémica que máis adiante se vai xerar no seo do sistema literario galego, entre os modelos literarios dos escritores do realismo máxico e os englobados dentro da Nova Narrativa Galega (...) xa está neste momento en funcionamento. (...) A polémica existe e maniféstase dentro da mente de Piñeiro, a través da súa análise da cultura europea do seu tempo, antes de que esta teña plasmación na literatura galega da época. (...) Esta anticipación, contra os modelos da literatura existencialista e obxectalista, herdeira de Kafka, resulta dun enorme interese desde o punto de vista histórico-literario (Forcadela 2005: 14).

\section{PIÑEIRO E OS NOVOS NARRADORES}

Os mozos con inquietudes intelectuais e artísticas que se achegaban a Compostela para iniciaren os estudos universitarios procuraban contactar con Piñeiro e participar dos faladoiros dos vellos galeguistas, con Otero Pedrayo á cabeza. Tanto as reunións no café Español como, sobre todo, os ben coñecidos encontros en Xelmírez 15, darredor da mítica mesa braseiro de Ramón Piñeiro, eran cita obrigada para quen pretendía incorporarse ao galeguismo e á cultura galega nos anos cincuenta. Piñeiro coñeceu e tratou a meirande parte dos mozos e mozas que compuxeron a nova xeración de narradores ${ }^{6}$. Mais, certamente, o grao de proximidade (e coincidencia) de criterio non foi o mesmo en todos os casos. Rodríguez Mourullo e Beiras foron dos primeiros mozos universitarios en incorporarse ao grupo galeguista e formaron, con Ramón Lugrís, o primeiro elo na

ka», Grial 33, 264-272; «Henri Miller: o «enfant terrible» norteamericano», Grial 37, 267-280; «Polos vieiros proustianos», Grial 53, 299-309

5 Varela Jácome, B., «Aspectos de la obra de William Faulkner», La Noche, 14-7-1962; «Las novelas de Hesse», La Noche, 13-8-1962; «La nueva novelística extranjera, en versiones españolas. La mejor aportación: el «relato objetivo» francés», La Noche, 8-12-1962; «Problemas de la novela actual. El cambio del enfoque narrativo», La Noche, 16-2-1963. Tamén no vespertino compostelán viron a luz diversos traballos sobre narradores europeos e americanos doutros autores: Martul Rey, P., «Faulkner y lo irracional», 9-12-1959; Ardións, J. L., «Nuevas tendencias de la novela americana», 27-4-1964; ou tamén García Bayón, C., «Camus en la aldea», 17-10-1960, así como os anónimos «Flores sobre la tumba de Faulkner», 14-7-1962, ou «Thomas Mann, a los diez años de su muerte», 8-7-1965, entre outros.

${ }^{6}$ Gonzalo Rodríguez Mourullo, Xosé Luís Méndez Ferrín, Camilo González Suárez-Llanos (Camilo Gonsar), M. ${ }^{a}$ Xosé Queizán, Xohana Torres, Carlos Casares e Xohán Casal. 
cadea que o galeguismo pretendía construír cara ao futuro. A partir de 1953 foise formando un pequeno núcleo, a modo de embrión, que aspiraba a «espallar entre outros compañeiros estas inquedanzas por todo o que se refería a Galicia e á cultura galega» (Castrelo 1979). Tamén falaban «a cotío das novas correntes literarias - en especial da novela americana» (Franco Grande 1985: 52) con Varela Jácome, bo coñecedor das novidades da literatura do século XX.

\subsection{O caso Mourullo}

A relación de Pîñeiro con Gonzalo Rodríguez Mourullo — novo valor das letras galegas - foi durante anos de trato cordial, como se indica neste fragmento de carta a Allué Andrade (19-11-1954) na que se fai eco do seu éxito: «Por eiquí os rapaces están moi animados. Un diles, o Gonzalo R. Mourullo, acaba de pubricar un libriño de contos galegos titulado Nasce un árbore que foi moi ben acollido» (Piñeiro 2005: 58). Dáse, xa que logo, coñecemento e seguimento da actividade literaria do novo narrador.

Efectivamente, rozando aínda a vintena, Mourullo publicara dúas coleccións de contos (Nasce un árbore, 1954 e Memorias de Tains, 1956), e contaba cun premio do Centro Galego de Buenos Aires (pola colección de contos Homes sinxelos). No cerne da súa escrita estaba a reivindicación da capacidade da lingua propia, mais sobre todo a conquista de todos os espazos posibles para a literatura galega. Tratábase de reivindicar o galego como«vehículo idóneo pra facer con el as mesmas experiencias de narrativa nova e de novas técnicas de narración que se facían naquel momento en Europa e en América» (López 1982).

Por parte da mocidade lectora, estas obras foron recibidas como unha auténtica revolución no discurso narrativo galego. Pero, segundo os presupostos estéticos imperantes nos vellos galeguistas de Galaxia, a recepción desde ese ámbito non podía ser igualmente positiva. Así, as obras de Rodríguez Mourullo recibiron valoracións máis ben negativas, que denotaban desacordo ou, cando menos, unha incomprensión dos textos, sobre todo no caso de Memorias de Tains. Así, baixo o pseudónimo de «Fernando Cadaval» e tras reprocharlle a Rodríguez as súas referencias literarias estranxeiras (Faulkner, Kafka), escribía Carballo Calero:

este joven escritor hace literatura de laboratorio, literatura experimental. Muy interesante. «Placet experiri». Pero la literatura experimental es, en realidad, preliteratura. Hay que salir del laboratorio. Los experimentos son por naturaleza algo previo. Mourullo ya ha hecho bastante gimnasia por el método Kafka o por el método Faulkner. Ahora debe echarse a la calle, solo (Carballo Calero 1956).

O rexeitamento desta obra por parte do sector dirixente, así como a publicación en Galaxia da obra de Daniel Cortezón, implicaba unha desautorización cara á orientación da narrativa de Mourullo que provocou o desencontro e a ruptura co círculo de Galaxia. Os valores estéticos presentes nos seus contos - caracterizados polo espazo non referencial, desintegración do personaxe, tratamento da angustia, do alleamento e da incomunicación, por exemplo, e baleiros 
do lirismo, humorismo e vivencia da paisaxe que representarían a «personalidade espiritual»- resultaban contraditorios co modelo propugnado por Piñeiro. A finais de 1956 a ruptura entre ambos xa atinxía non só o plano intelectual senón tamén o persoal (Bermúdez 2002: 145-151). Certamente, no plano literario, as diverxencias de Mourullo con Galaxia respecto da estética que defendía eran profundas. Por isto negarase a admitir directrices en torno á estética e ao concepto de literatura.

Piñeiro expresou a súa posición sen matizacións nin disimulo no ámbito da intimidade epistolar con Carballo Calero, como se fai patente neste parágrafo (15-1-1957):

Comparto plenamente as consideracións que fas tocante o desequilibrio que se bota de ver nas nosas letras, demasiado entregadas ás correntes ultrapirenaicas e pouco arraizadas no chan galego. Confío en que non pasará de ser unha simpática petulancia xuvenil da nosa cultura, sin chegar a se convertir en $d o-$ enza crónica. Mais tamén me parece moi san e comenente que os que temos algunha responsabilidade no decorrer aitual da nosa cultura nos preocupemos de tal fenómeno no que ten de aberrante» (Alonso Girgado 2004: 50-51). [Cursiva nosa]

Esta referencia á «petulancia xuvenil», ao «desequilibrio» existente e ao fenómeno «aberrante» - capaz de provocar preocupación aos responsables «da nosa cultura»- diríxese con certeza ás innovacións técnicas e temáticas introducidas por Rodríguez Mourullo, iniciador do que se denominaría máis adiante «nova narrativa galega». Sen dúbida, como indicou Forcadela (2005), pódese falar de oposición - latente, nun primeiro momento, explícita, máis tarde- entre dúas concepcións da literatura nesa etapa, que se proxectan sobre dous modelos de narrativa galega.

A «Carta a Manuel Antonio» (La Noche, 26-1-1957) representa a resposta pública de Mourullo ás teses piñeiristas, ben como a exposición do seu posicionamento como escritor galego. Neste sentido, Mourullo erixiuse en voceiro dos que non concordaban nin co modelo proposto nin co dirixismo en si, e a «Carta» representou o testemuño grazas ao cal aflorou publicamente un debate que permanecera, ata entón, latente. No texto, Mourullo bota man do paralelismo coa peripecia literaria de Manuel Antonio, que coñece en profundidade, e aproveita a súa figura para defender os propios posicionamentos estéticos e denunciar unha incomprensión por ambos sufrida. A «Carta a Manuel Antonio» artéllase como resposta á «Carta a Daniel Cortezón Álvarez» (Piñeiro 1956a), e foi entendida como un emblema de vangarda en oposición a ela ${ }^{7}$. Máis alá desta analoxía, a

${ }^{7}$ Constata Ferrín a existencia dun enfrontamento entre dúas maneiras de concibir a función da produción literaria e entre os diferentes modelos estéticos nados delas, no seo da Galicia da época (década dos cincuenta-sesenta). Afirma así: «En 1956 están coas espadas levantadas dúas concepcións da narración. Unha, a que representabamos nós, os que despois nos chamamos "nova narrativa galega". Outra, a representada por Álvaro Cunqueiro e Ánxel Fole. Ramón Piñeiro é o teórico da posición Álvaro Cunqueiro-Ánxel Fole. Mourullo habería de ser o teórico da posición contraria nun famoso texto titulado "Carta a Manuel Antonio"» (Méndez Ferrín 1999: 9-33). 
«Carta» ten como destinataria primeira a órbita de Galaxia; porén, calou fondo nos novos autores, como texto reivindicativo doutra posibilidade de entender a literatura galega, alleo a «personalidades espirituais». Mourullo rexeita os argumentos contrarios ao seu xeito de narrar destilados en diferentes textos: critica o concepto de escola e de imitación, nega a acusación de desarraigo do país por fuxir do localismo, cuestiona a teima recorrente de volver ao pasado (isto é, o gusto polo «neo» e a recreación do vello), e en definitiva a consideración de que a literatura de Galicia camiña á parte de todo, allea ao mundo e á época (Rodríguez Mourullo 1957).

Da náuseas la crítica, Manuel Antonio. Esta crítica —-la gallega — llena de prejuicios y pasiones. Esperemos que llegue el extranjero o, lo prefieres, que llegue pasado mañana. Ahora hablemos sólo de tu lección. Te empapaste en la literatura europea de tu época e hiciste desde Rianjo literatura europea. Nada de localismo, nada de aldeanismos. ¿Literatura gallega? Para nosotros sí. No sé hasta que punto para los corifeos. Quizás prevalezca en ti con más intensidad el influjo de la época que el influjo del país. ¿País? ¿Época? Uno está «sobre» el país y «en» la época. El país es como el suelo sobre el que ponemos nuestros pies y la época como la atmósfera que respiramos. Aquellos que se clavan en el país dan la impresión de que se entierran, se hunden en la tierra. Aquellos que se dejan llevar demasiado por la época dan la impresión de que se levantan del suelo y emprenden un vuelo que les producirá el olvido de «sus» cosas. Pero existe una diferencia grande entre uno y otro exceso: los que se entierran perecen fatalmente por asfixia, los que vuelan no corren nunca este riesgo. Tú no quisiste enterrarte, desde luego. Preferiste desenterrar lo que irremediablemente estaba condenado a morir. Tendiste tu mano desinteresada a los que se iban a asfixiar. Esta es tu gran lección.

Para los corifeos son sospechosos todos aquellos que viven con intensidad los problemas de la época. Hay que volver siempre atrás, llenar los vacíos, no romper la continuidad. Pero la Historia es la gran película que marcha siempre en la misma dirección: impresiona cuando hay algo que impresionar, y queda en blanco cuando no hay nada. (...) Obedecer al influjo de la época es peligroso para la literatura gallega. Hay que volver, siempre volver, localizar, raquitizar la obra.

(...) Que se diga que es importante cultivar y no descuidar este tipo de literatura, me parece más o menos discutible. Que se diga que esa es la dirección a seguir, me parece una soberana estupidez, como te parecía a ti, humilde marinero, que has dado la mejor de las lecciones en la Historia de la literatura gallega. Pues eso es lo que se nos dice (Rodríguez Mourullo 1957) [cursiva nosa].

A «Carta» suporá a despedida literaria do autor, quen a partir dese momento abandonará a escrita en galego - á parte dun conto nun volume colectivo (Rodríguez Mourullo 1983) - e a participación activa nos círculos galeguistas. O distanciamento estético levou aparellado un distanciamento político, como testemuña esta carta de Franco Grande a Piñeiro (xuño de 1957): 
No pouco tempo que puiden falar con Paco [Fernández del Riego], entereime de que o Gonzalo [Rodríguez Mourullo] parece que anda medio metido nunha cousa que lle chaman «Juventud Socialista». ¿Que é iso? Sinto que ande metido nisas cousas, pois isto será unha terceira caída que non lle convén nada. Así que non o reconozan como «cabeza», mandará todo ó paseo. Il mesmo anda a percurar a propia caída (Piñeiro / Franco Grande 2009: 57).

As novas xeracións galegas, con Mourullo como pioneiro, procurarán novas ferramentas expresivas, en consonancia coas necesidades da época. Neste sentido, considérase que Mourullo achegou unha nova actitude á nosa literatura, depurada de complexos, receptiva ao espírito da época e aos aires de actualización da narrativa contemporánea, europea e norteamericana. Unha obra innovadora sempre tenta unha ruptura no horizonte de expectativa do público, segundo afirma D.H. Pageaux. Deste xeito, «a aceptación progresiva de obras innovadoras na súa época explícase pola evolución do gusto, dos criterios de apreciación dun público (e dunha crítica) respecto dun horizonte de expectativa inicialmente rexeitado» (Pageaux 1994: 51). Ese foi o caso das obras de Mourullo (sobre todo Memorias de Tains), que non logra romper co horizonte de expectativas dos máis vellos, mais consegue encaixar cos gustos dos novos, feito que propiciará un cambio progresivo na década seguinte.

Con todo, a achega innovadora da narrativa de Mourullo foi recoñecida por académicos relacionados con Galaxia, aínda sen integraren o círculo compostelán, como é o caso do profesor Basilio Losada, quen valoraba moi positivamente a obra de Mourullo e se interesaba desde Barcelona pola súa traxectoria (21-11962):

E ¿que foi de Gonzalo R. Mourullo? Lin hai anos as súas obriñas e impresionoume moi ben; logo ven o silenzo destes anos, un pouco inespricable. Mourullo, Ferrín e mais Suárez-Llanos puideran ser os nosos primeiros narradores de xeito nidiamente europeo. Porque Cunqueiro, que é rigorosamente xenial, é demasiado persoal, e calqueira influencia que exerza será unha sinxela e nefasta imitación» (Piñeiro / Losada 2009: 103).

A resposta de Piñeiro (3-2-1962) resulta certamente esclarecedora da súa opinión respecto do escritor e novo xurista Rodríguez Mourullo, como se ve a seguir:

Pregúntame por Mourullo. Está en Madrid, de Axudante do profesor Del Rosal, consagrado á preparación prá cátedra de Dereito Penal, ó que lle ten gran afición. Coido que arredou toda aitividade ou inquedanza que seña allea á preparación científica e diplomática da cátedra, mais a min paréceme que, unha vez conquerido ise ouxetivo - il é francamente intelixente e sairá adiante-, non deixará de voltar á literatura, prá que ten vocación e aptitudes. Trátase dunha persoalidade complexa: fortemente introvertido; moi intelixente; ambicioso; dotado dun amor propio tan hiperestésico como silencioso; moi cerebral no seu obrar, incluso no seu obrar literario, i ó mesmo tempo con un fondo temperamental apasionado e aínda unha miga turbulento; dun ego- 
tismo [sic] fundamental; inclinado íntimamente a unha visión crítica e bastante aceda da vida; pouco dado á quentura xenerosa e cordial; moi reservado no pensar, moi cauteloso no obrar, moi desconfiado no interpretar. En fin, como pode verse trátase dunha persoalidade de rasgos moi acusados e dabondo polarizados entre sí pra crearen fortes tensións interiores. Si volta á literatura, como cabe agardar, poderá facer unha obra interesante, porque il non ten nada de vulgar. Pola contra, ten indudábel talento (Piñeiro / Losada 2009: 106-107).

Piñeiro caracteriza a Rodríguez Mourullo con termos como «cerebral» (paradoxalmente combinado cun fondo «apaixonado»), «reservado», cunha visión «crítica» e «aceda» da existencia, malia recoñecerlle tamén un «indudábel talento», «vocación»e «aptitudes». O adxectivo cerebral remítenos ao racional e ao racionalismo que, como vimos antes, no xogo de oposicións posto de manifesto por Forcadela (2005) se sitúa no pólo oposto dos trazos típicos da galeguidade, segundo o ideoloxema de Piñeiro.

\subsection{Máis alá da «Carta a Manuel Antonio»}

O abandono de Mourullo non podía deixar de provocar unha situación de incomodidade entre a mocidade galeguista. Certamente, as diverxencias estéticas eran compartidas por outros membros da nova xeración, da que Mourullo foi, sen dúbida, voceiro. Outros, como Méndez Ferrín, non tardarán en expresar as súas discrepancias e en pedirlle explicacións a Piñeiro:

espúxenlle as miñas dúbidas de que polo camiño que el tiña trazado non se ía ben e, sobre todo, pedinlle que este grupo se organizase como tiña que organizarse, como órgano partidario (Salgado 1989: 77).

Para os novos resultaba clara a mensaxe de Piñeiro: propugnaba a inconveniencia de que os escritores galegos escribisen como os escritores do seu tempo noutros lugares do mundo, porque era aquel un tempo de carencia de liberdade e de masificación do que só estaba a salvo Galicia (Méndez Ferrín 1993):

Mellor dito, o que quere dicir é: vivimos nun mundo de predominio do comunismo, nas letras, non só na Unión Soviética; en Francia, nos Estados Unidos, tamén. Polo tanto, hai que ir a unha escrita da liberdade. Como Galicia, privilexiadamente, está fóra das correntes do noso tempo, aínda existe a vivencia da liberdade íntima. A liberdade íntima debe manifestarse na literatura a través da fantasía, como Álvaro Cunqueiro (...). Ou ben debemos facer como Ánxel Fole: sotilmente mesturar os mitos e os prodixios tradicionais coa ubicación na realidade rural. Ou tamén podemos ser libres sendo humoristas ou sendo líricos puros. Este sería o programa (Méndez Ferrín 1999: 27-28)

Como vimos, «Galicia, o pobo galego, é un pobo privilexiado — chega a escribir a palabra «raza», Ramón Piñeiro-, é un pobo privilexiado porque é o único pobo que ten a vivencia radical da liberdade» (Méndez Ferrín 1999: 28) 
nunha liña de pensamento que se insire no ámbito da «filosofía da saudade». Para Piñeiro

a Saudade e a soedade ontolóxica é algo que é privilexio exclusivo dos galegos e dos portugueses e que, polo tanto, a filosofía galaico-portuguesa é algo só noso que nós debemos construír sobre a vivencia da Liberdade. Polo tanto, non debemos atender os cantos de serea existencialistas, nin os cantos de serea neokantianos, porque iso é a filosofía dos outros, non a dos galegos. Este profundo reaccionarismo, este profundo fundamentalismo piñeiriano aplícase tamén á literatura (Méndez Ferrín 1999: 28).

Xa que logo, o proxecto culturalista de Piñeiro e o grupo Galaxia provocou un conflito xeracional, un choque coas expectativas e a vontade de independencia de Ferrín, como xa acontecera con Rodríguez Mourullo:

É curioso como naqueles anos Rodríguez Mourullo, Méndez Ferrín, Xohán Casal e Camilo G. Suárez Llanos pensaban nunha nova narrativa galega, en inxertar na nosa prosa xermes do que polo mundo se viña facendo, e como todos eles tiñan talentos fóra do común para conseguilo. Por iso comprendo moi ben o alporizamento de Ferrín, ou de Mourullo, coas ideas que Piñeiro expoñía nos seus prólogos ó libro de Cortezón, pois, como decía Ferrín, Piñeiro déixanos fóra da literatura (Franco Grande 1985: 97).

Méndez Ferrín mantén nos anos cincuenta unha intensa relación con Piñeiro e o seu grupo de Santiago (Franco Grande 1985). En todo caso, a actitude do núcleo galaxiano cara a Ferrín era moi favorable. Certamente, Ramón Piñeiro acollía con satisfacción os éxitos dos rapaces que se ían incorporando á célula galeguista compostelá e expresábao en cartas dirixidas a Fernández del Riego (23-3-1956), a quen escribe sobre Ferrín, con intención de integralo no proxecto cultural que se estaba a desenvolver:

Foi a gran revelación literaria deste concurso universitario. Felizmente, é un escritor galego e non pretende ser outra cousa. Será, de certo, un dos anovadores da nosa prosa literaria, pois ten verdadeira vocación de escritor. Ten, ademais, ideas moi craras sobre a súa adicación cultural. (...) Pono en relación cos amigos de ahí (Fernández del Riego 2000: 107).

O paratexto da primeira obra de Méndez Ferrín testemuña dese apadriñamento. Percival e outras historias (1958) contou cunha dedicatoria a «Otero Pedrayo e Ramón Piñeiro, mestres» e contou cun limiar de Francisco Fernández del Riego (Salvador Lorenzana), quen sinalaba o xurdimento dunha «nova promoción galega». E salientaba a importancia «vital» para un país «dun equipo de narradores». Destacaba ademais a preponderancia da técnica fronte ao argumento, a configuración dunha atmosfera de irrealidade e, asemade, a pegada de William Faulkner, Franz Kafka e Marcel Aymé, pola súa vinculación co realismo fantástico. En definitiva, Fernández del Riego salientaba nesta presentación a pertenza a unha corrente de innovación e modernización narrativa protagonizada pola nova xeración que comezaba a agromar. Por outra banda, $O$ 
crepúsculo e as formigas (1961) foi respaldado por Piñeiro como autor dun prólogo, no que apoiaba decididamente o autor e expresaba unha confianza plena na súa futura carreira literaria galega. Ao longo da décadas dos sesenta irá materializándose un afastamento que atinxiu tanto o plano estético como político. Méndez Ferrín así o manifestou en diversas ocasións:

E entón a súa concepción da literatura estaba en contradicción, desde logo, coa miña. El, no seu maquiavelismo tratou de poñerme de substituto de Mourullo. Sen éxito. Pero xa que Mourullo se ía el tratou de animarme. Eu non quixen participar nin dese xogo nin dese grupo. Xa a partir do ano 58, cando se forma o grupo Brais Pinto en Madrid hai cada vez menos contacto, e xa nos anos 60, no 63, ao empezar o Consello da Mocidade, a UPG o enfrontamento foi político e total (Bermúdez 2002: CXIX).

Deste xeito, segundo o testemuño do propio Ferrín, este non aceptou exercer o papel de «substituto de Mourullo»—que fora o mozo máis destacado entre aqueles que participaban do círculo de Galaxia - tras o seu abandono. A integración de Méndez Ferrín en Brais Pinto foi decisiva, nese sentido. Á altura de 1964, os integrantes de Brais Pinto xa se sentían enfrontados co núcleo piñeirista. Da man dunhas diferenzas xurdidas no plano político - pois o posicionamento dos novos acabou irremisiblemente lonxe do europeísmo pactista e antimarxista do núcleo santiagués- camiñaban tamén as diverxencias nas concepcións estéticas, como xa apuntamos. Brais Pinto

combate, por unha banda, a concepción piñeirista da novela, favorábel á liña cunqueirana, solidarizándose cos que, como Casal e Mourullo, incorporaban as novas técnicas e o novo pathos épico do tempo posterior á II Guerra Mundial, achegándose tamén ao traballo de Camilo Gonsar e Franco Grande (...). No plano político, Brais Pinto senta a necesidade de acción política nacionalista fronte ao abandono por parte do grupo piñeirista dos presupostos de autodeterminación nacional e fronte á súa apraxia culturalista, acción política que se intentara no consello da Mocedade, fracasado (Méndez Ferrín 1993: 410).

\subsection{A posición de Xohán Casal. Galaxia e Brais Pinto}

Mesmo Xohán Casal, relativamente illado pola súa doenza na Coruña, se relacionou co círculo de Galaxia. Casal mantivo unha reveladora relación epistolar con Xosé Luís Franco Grande, responsable do seu achegamento ao círculo de Piñeiro e era tamén suscritor de Galaxia. Foi Casal quen procurou iniciar unha correspondencia con Franco Grande na que se desenvolveron interesantísimos debates estéticos. A conexión resultou moi enriquecedora para Casal, segundo el mesmo confesa no seu diario (8-10-1957):

Todos istes días andiven a facer grandes descobrimentos. Dend'a pirmeira carta que recebín de X.L.F.G. entrei en movimento. Espertoume. Logo coa segunda púxome perante uns problemas moi duros de rillar. Tiven que lles dar 
cara e d'eles vai saíndo unha fonda solución pra miña vida (Arquivo da Real Academia Galega).

No intercambio de ideas entre ambos, destaca un intenso e apaixonado debate darredor da «Carta a Daniel Cortezón Álvarez» (Piñeiro 1956a). Nun primeiro momento, Casal expresa a súa reticencia (carta 2-10-1957) ante a exclusión que deseña Piñeiro:

Ista mañán, moi cedo, collín «As covas do Rei Cintolo» e leín o limiar. Somentes o lêra unha vegada, hoxe, pouco a pouco, funo papando todiño, pra ficar arrepiado.

¡Agora xa sei como é que non conquería xeito de falarche! Cando leín iste limiar de Piñeiro, ollei que me condeaba duramente. ¿Era iso tamén o que ti queriasme dir cando referíndote â miña doenza e aos meus escritos decias que o meu «Eu» predomiñaba subliñadamente, c’un âr demoucado e pesimista? ¡Entón estaba fora da literatura galega! (Arquivo da Real Academia Galega)

Posteriormente, dáse certo achegamento coa postura propugnada por Piñeiro e defendida por Franco Grande. Este congratúlase da aproximación do mozo coruñés aos seus posicionamentos:

Indo xa ós nosos derradeiros temas, debo decirche que me aledo moito de que caletraras ben o limiar de Piñeiro ás «Covas do Rei Centolo». Eu penso que nil está tratado, con moita intelixencia e rigor, un dos máis serios probremas espritoás do noso tempo. Coido que non haberá aínda en toda Europa unha formulación máis seria e consciente de un grave e arrepiante probrema do noso tempo. Medítao ben e xa verás o celme europeo e galego que zumega disas poucas páxinas. Ó meu ver, hai soterrado nelas a millor comprensión que, no eido da cultura, debe ser a «galicidade» (Arquivo da Real Academia Galega).

Só xa na véspera da súa morte (10-1-1960) lograría viaxar a Compostela para establecer contacto persoal con Piñeiro e o núcleo galeguista. Nese encontro, Piñeiro propúxolle en nome de Galaxia publicar os seus contos na colección «Illa Nova». Tempo antes (carta a Camilo Gonsar, 13-12-1954), xa Piñeiro fixera referencia a un volume de contos que Casal estaba a preparar en galego, co que cabe deducir que cabía o proxecto dunha publicación da obra (Bermúdez 2002: 208). Franco Grande era o enlace de Casal co grupo galaxiano, feito que se evidencia nesta carta do poeta de Tebra a Piñeiro (outubro de 1957):

O Casal Pardo sigue a falarme da raza, da cultura e do telúrico. De día a día vou confirmando a súa intelixencia e outura de esprito. Trátase de un rapaz que ten moi «rumiadas» moitas cousas nos anos en que estivo soio que foron bastantes. De día a día síntome máis interesado por il, pois comprende moi ben o que se lle di, dálle voltas e voltas ás cousas hasta que entra moi dentro delas. Está dito tudo si lle digo que é un home que toma as cousas en serio. Agora, coa nosa correspondencia, está a vivir unhos días, ou unha etapa, chea de en- 
tusiasmo e de eilusión. Teño moitas ganas de conocel-o persoalmente. É interesante de verdade. Escríbeme cartas de 4 e 5 folios cheas de interés, moi equilibradas e nas que se ve que xa vai «crarexando» moitas ideas que antes eran confusas. Como pode imaxinar, ista é a máisima satisfaición da miña vida e a meirande que me puido producir a publicación do meu libro [Vieiro choído]» (Piñeiro / Franco Grande 2009: 67).

Ademais dos contactos con Galaxia para publicar a súa obra, Casal mantiña unha intensa relación cos mozos de Brais Pinto (galegos residentes en Madrid), do que formaba parte o seu amigo Reimundo Patiño. Finalmente, a colección de contos $O$ camiño de abaixo viu a luz de xeito póstumo, en 1970, precisamente grazas a Patiño. Na súa correspondencia con Franco Grande, en todo caso, Casal deixou exposto o seu posicionamento estético, inicialmente en desacordo cos presupostos piñeiristas:

Eu non podo pensar en mólidas saudades, en teimas filosóficas. (...) ¡Qué máis quixera eu que vivir na rua Xelmírez preto de Piñeiro! (...) Máis eu ch'ando pol-os peiraos cos homes chegados do mar, ou cos obreiros, positivistas, materiales (...), pro eu sei ouvir a verdadeira poesía que acochan as suas verbas. Zecáis (sic) isto —e a prena concencia decidin adoitar unha posizón pouco galega na sua tona - fíxome adequerir un âr molesto pra vós (Bermúdez 2002: IV-V) [A cursiva reproduce o subliñado de Casal].

Casal reivindica o elemento urbano e de clase obreira que xa existe en Galicia, no que supón un desencontro coas ideas do grupo piñeirista expresado no plano estético-literario, pero non exento de base ideolóxica. A idealización do campo, a filosofía da saudade e o cultivo dos mitos oponse á conflitividade social emerxente, á problemática cotiá no ámbito urbano, á realidade material vivida polos galegos e galegas, á pobreza, á explotación e á marxinalidade no propio país, a ausencia de recoñecemento de dereitos sociais. Casal non admite que o feito de desbotar determinados temas («fadas», «trobadores» e «mólidas saudades») supoña falta de galeguidade. Nega tamén que quen faga tal cousa ten de ser necesariamente un mero importador de estilos e intereses estranxeiros. Oponse así a aqueles que cualificaban de alleo todo o que non reproducise unha determinada realidade rural e esencial: estranxeiro ao «ser galego» apegado ás tradicións, á «vivencia da paisaxe» e á representación das esencias eternas que os homes de Galaxia promovían como temas prioritarios antes de fixarse en «mundos alleos», isto é, en mundos distintos do considerado auténtico reflexo da «personalidade espiritual» galega.

Casal propugna un modelo de literatura capaz de reflectir a realidade plural do país, sen limitarse a un ruralismo por veces sentimentaloide nin lanzarse á procura dunha hipotética cerna inmorredoira do ser galego. Isto supón un claro contraste cunha estética galaxiana centrada, como vimos, na actualización nunha determinada dirección das esencias da identidade nacional galega. Tamén nas reflexións críticas que foi recollendo nalgunhas pasaxes do seu diario (Casal 1970), lanza ao aire as cuestións que son obxecto da súa preocupación, cunha aguda sensibilidade respecto da oposición entre campo e cidade a partir da dé- 
cada dos cincuenta, e a reivindicación do espazo literario da Galicia urbana (Bermúdez 2002: 221-222). En definitiva, reivindica poder ocupar tamén un espazo, complementario e non excluínte doutras estéticas.

Eu coido que a galeguidade non é unha cousa astraita e privativa d'uns poucos como pra andar xugando con ela (...). Cada ún de nós olla unha faceta distinta d'unha mesma verdade. Todas elas xuntas fán a verdade de Galiza (Bermúdez 2002: V).

\subsection{Unha colección para os novos: «Illa nova»}

A polémica xerada darredor do abandono de Mourullo fixo evidente que a nova xeración que estaba a incorporarse á escrita en galego precisaba dun lugar propio para desenvolverse. Pódese considerar que, indirectamente, o agromar da rebeldía dos «novos narradores» tivo consecuencias positivas: a apertura dun espazo de creación exclusivo para a nova xeración, a colección «Illa Nova». Piñeiro escribía a Allué (24-1-1957) en relación coas novas expectativas e o entusiasmo: «Os rapaces deiquí están cheos de entusiasmo. De agora en adiante dispoñerán dunha nova coleición de Galaxia creada pra iles e por iles dirixida» (Piñeiro 2005: 85).

A correspondencia de Piñeiro revela a súa proximidade cos novos autores e autoras, así como o interese co que seguía o seu proceso de creación. Este é o caso de Camilo Gonsar (González / Lama 2009) ou de Xohana Torres, por exemplo, a quen recoñece «indudábel talento» e en quen ten posta a confianza de que leve a cabo «cousas interesantes» (Alonso Girgado 2004: 51). Xa en 1962 (carta a Carballo Calero, 15-1-1962) Piñeiro refírese a unha novela na que a autora tiña traballado moito (presumiblemente, Adiós María, que verá a luz case unha década máis tarde).

Finalmente, desde a óptica de Piñeiro e do grupo Galaxia, Carlos Casares había de ser a figura que representase a conciliación, a harmonización da personalidade de Galicia coa modernidade e o universal, o equilibrio posible entre galeguidade e «nova narrativa» (Bermúdez 2009).

\section{A MODO DE CONCLUSIÓN}

Ramón Piñeiro foi a figura clave do galeguismo de posguerra e desempeñou, incuestionablemente, un papel central no movemento de recuperación cultural galega que liderou a editorial Galaxia. Desde esa posición, mantivo estreitos contactos cos novos autores que pretenderon renovar a narrativa galega, aqueles englobados tradicionalmente na «nova narrativa». A súa figura intelectual resulta indispensable para entendermos os movementos culturais e de pensamento político no cadro da represión franquista e tamén da transición política. Sexa por identificación ou por oposición, as diversas posturas defínense a partir dun punto cero: Ramón Piñeiro. 
Ao longo deste traballo, pretendemos amosar -mediante documentos e testemuños nalgúns casos inéditos- os debates estéticos que tiveron a Piñeiro como eixo na década dos cincuenta do século pasado, nos albores da «nova narrativa».

\section{BIBLIOGRAFÍA}

Alonso Girgado, L. / Cuquejo Enríquez, M. / Fariña Miranda, C. (eds.) (2004): Cartas de Ramón Piñeiro a Ricardo Carballo Calero. Cadernos Ramón Piñeiro V. Santiago: Xunta de Galicia-CIRP.

Angueira, A. (2009): A espiral no espello. Vigo: Xerais, colección universitaria.

Bermúdez Montes, M. T. (1996): «Gonzalo R. Mourullo na narrativa galega», Anuario de Estudios Literarios Galegos 1995, 39-61.

- (2002): A narrativa galega de posguerra. Os intentos de renovación (1950-1971)». Tese de Doutoramento (inédita). Universidade da Coruña.

- (2001): Nasce un arbre. Memorias de Tains. Vigo Xerais.

- (2005): O camiño de abaixo. Vigo: Xerais.

- (2009): «Carlos Casares e a nova narrativa galega». Revista de Investigación en Educación. N. ${ }^{\circ}$ 6. Pontevedra: Facultade de Ciencias da Educación e do Deporte.

Carballo Calero, R. [Cadaval, F.] (1956): «Kafka, Faulkner y otras kaes», La Noche, 7-7-1956.

CunQueIro, A. (1963): «Imaxinación e creación. Notas pra unha conferencia», Grial 2. $179-184$.

FERNÁNDEZ DE LA VEGA, C. (1958): «Abrente e solpor da paisaxe», in VV.AA., Homenaxe a Ramón Otero Pedrayo no LXX aniversario do seu nacimento. Vigo: Galaxia. $103-128$

FERNÁNDEZ DEL RIEGo, F. (1996): A xeración Galaxia. Vigo: Galaxia.

- (2000): Un epistolario de Ramón Piñeiro. Vigo: Galaxia.

Fernández FreixANES, V. (1982): «Xosé Luís Méndez Ferrín, literatura e compromisos», in Unha ducia de galegos. Vigo: Galaxia.

Forcadela, M. (2005): Diálogos na néboa: Álvaro Cunqueiro e Ramón Piñeiro na xénese da literatura galega de posguerra. Cadernos Ramón Piñeiro VIII. Santiago: Xunta de Galicia-CIRP.

Franco Grande, X. L. (1968): «A lus do candil, por Ánxel Fole», Grial 21, 366-368.

- (1973): «Introducción a Álvaro Cunqueiro», Grial 42, 403-416.

- (1985): Os anos escuros. A resistencia cultural na xeración da Noite (1954-1960). Vigo: Xerais.

GonZÁlez FernánDeZ, H. (2001): «Galícia, o com subjectivar la diferència», Congrès Internacional Álvaro Cunqueiro i Catalunya. Bellaterra: Universitat Autònoma de Barcelona, 22-24 de novembro de 2001.

GonZÁLEZ MilLáN, X. (1995): «Do nacionalismo literario a unha literatura nacional. Hi- 
póteses de traballo para un estudio institucional da literatura galega», Anuario de Estudios Literarios Galegos 1994. Vigo: Galaxia, 67-81.

LóPEZ, F. (1982): «Un silencio a punto de romperse. Conversa con Gonzalo R. Mourullo», La Voz de Galicia, Suplemento de Cultura, 13-5-1982.

MÉndez Ferrín, X. L. (1984): De Pondal a Novoneyra. Vigo: Xerais.

- (1993): «A Gadaña no mundo», A Trabe de Ouro, 15, tomo III, 409-420.

- (1999): «Unha leitura de Álvaro Cunqueiro», in Méndez Ferrín, X. L. / Pallarés, P. / Álvarez Cáccamo, X. M. ${ }^{a}$, Clásicos e modernos. Tres leituras poéticas. A Coruña: Universidade da Coruña, 9-33.

Noia CAmpos, M. ${ }^{\text {a }}$ Camiño (2002): «A narrativa de posguerra», in Proxecto Galicia. Literatura, Tomo XXXIV. A Coruña: Hércules de Ediciones.

Pageaux, D.-H. (1994): La littérature générale et comparée. Paris: Armand Colin.

PIÑEIRO, R. (1951): «Carta a Álvaro Cunqueiro, trovador galego, falándolle dos males presentes de Europa e do seu remedio, dende a ladeira dun castro lugués». Grial $\mathrm{Ca}$ dernos 3 [Presencia de Curros y D. Emilia]. Vigo: Galaxia, 103-107.

- (1951): «Siñificado metafísico da saudade. Notas pra unha filosofía galaico-portuguesa». Grial Cadernos. Vigo: Galaxia.

- (1956a): «Carta a Daniel Cortezón Álvarez», in Cortezón, D., As covas do Rei Cintolo. Galaxia, Vigo.

- (1956b): «Carta a Novoneyra», in Novoneyra, U., Os Eidos, Vigo: Galaxia.

- (1965): Paisaxe e cultura, Vigo: Galaxia, Colección Ensaios.

- (1974): Olladas no futuro. Vigo: Galaxia.

— (1987): «Os contos de Ánxel Fole», Grial 95, 113-114.

- (2002): Da miña acordanza. Memorias, Vigo: Galaxia-Fundación Caixa Galicia.

- (2005): Cartas a un mozo galego. Correspondencia con Xosé Luís Allué 1953-1967, Vigo: Galaxia.

Piñeiro, R. / Losada, B. (2009): Do sentimento á conciencia de Galicia. Correspondencia (1961-1984). Vigo: Galaxia-Xunta de Galicia.

QueIZÁn, M. X. (1979): «A nova narrativa ou a loita contra o sentimentalismo», Grial 63, xaneiro-marzo 1979, 67-80.

RodríGuez Mourullo, G. (1957): «Carta a Manuel Antonio», La Noche. 26-1-1957.

SAlgado, X.M. (1989): X.L. Méndez Ferrín. Barcelona: Sotelo Blanco.

VV.AA. (1951): Presencia de Galicia, Colección Grial 3. Vigo: Galaxia.

- (1991): Grial 111. Vigo: Galaxia. 